\title{
Pain with life-threatening illness: Its perception and control are inextricably linked with quality of life
}

\author{
S Robin Cohen PhD, Balfour M Mount MD FRCSC
}

\section{SR Cohen, BM Mount.}

Pain with life-threatening illness: Its perception and control are inextricably linked with quality of life.

Pain Res Manage 2000;5(4):271-275.

This article describes how the quality of life of people with a lifethreatening illness is affected by pain, and how their pain is influenced by all aspects of their quality of life. These aspects include the physical, psychological, cognitive, social, and spiritual and existential domains. This concept of pain is placed in the context of Ron Melzack's work highlighting the essential role of cognitive and emotional aspects of pain perception, and their influence on pain control. These issues continue to be a guiding force in the authors' own work and that of many others working in the field.

Key Words: Cancer pain; Palliative care; Psychology; Quality of life; Social domain; Spirituality

\section{La douleur dans la maladie gravissime : Sa} perception et son contrôle sont intimement liés à la qualité de vie

RÉSUMÉ : Cet article décrit de quelle façon la qualité de vie des gens qui souffrent d'une maladie à potentiel fatal est affectée par la douleur et l'influence de tous les aspects de la qualité de vie sur la douleur. Ces aspects incluent les domaines physique, psychologique, cognitif, social et spirituel et existentiel. Cette notion de la douleur est placée dans le contexte des travaux de Ron Melzack qui soulignent le rôle essentiel des aspects cognitifs et émotionnels de la perception de la douleur et leur influence sur le contrôle de la douleur. Ces questions continuent de motiver nos propres travaux et ceux de nombreux autres spécialistes du domaines.
W e have both treasured our relationships with Ron Melzack. From the earliest days of the Canadian palliative care experience, Ron offered Balfour Mount his enthusiastic support in establishing sound research data to document the efficacy of the palliative care approach to pain control (1). Robin Cohen was supervised by Ron for her graduate studies, which focused on the neuroanatomy of pain and analgesia, with particular emphasis on the forebrain, at a time when this region of the brain was largely ignored in pain research. One of the most important things that Ron taught her was the value of creativity and reflective time in scientific endeavours. While the field of palliative care may seem a far cry from Ron's animal laboratory, when Robin switched to palliative care (with the help of Ron's introduction to Balfour) it was immediately clear that the lessons learned in Ron's laboratory needed to be applied in the palliative care setting, where the contributors to pain are much more diverse than simply tissue injury and abnormal physiology. Furthermore, relief of the pain of palliative care patients demands consideration of a wide range of variables that vary with the subjective experience of the sufferer. Quality of life (which we define as subjective well-being) must, therefore, be measured in addition to pain. We have developed the McGill Quality of Life Questionnaire to address this need (2-5).

Ron Melzack taught us many things, but that which has most clearly guided our research is that pain is not simply the result of a bodily insult, but rather the result of the interaction among the physical, psychological and cognitive states of the person in pain $(6,7)$. His emphasis that pain is a perception rather than a sensation has served as a model for our work concerning both pain and quality of life for people with a lifethreatening illness. The gate-control theory makes it clear

Division of Palliative Care, Department of Oncology, McGill University, and Department of Medicine, McGill University Health Centre, Montreal, Quebec

Correspondence and reprints: Dr SR Cohen, Palliative Care McGill, Ross 6.10, 687 Pine Avenue West, Montreal, Quebec H3A 1A1.

Telephone 514-842-1231 ext 5158,fax 514-843-1471, e-mail mcob@musica.mcgill.ca 
that, while different contributors to pain can be studied separately, unless all contributors are taken into account and the way in which they interact is understood, we will not have a complete picture but instead only individual pieces to a puzzle. This applies to both animal and human studies. In the palliative care setting in which we work, Saunders (8) used the term 'total pain' to direct attention to the reality that pain in terminal illness has contributors that are physical, psychological, financial, interpersonal and spiritual.

In the case of life-threatening illness, all aspects of the person are affected. To enable the person to have the best quality of life possible, all aspects that are disturbed must be addressed in order to restore equilibrium. The situation is usually complex. For example, to understand and treat cancer pain, we need to understand not only the physiological origin of the pain (destruction caused by the tumour or pressure from the tumour on another structure, or by radiotherapy, chemotherapy, surgery or a coexisting condition), but also its meaning to the patient (for example, the cancer is advancing and I will die; this is a punishment from God), as well as the patient's emotional state and social situation $(9,10)$. In our studies of quality of life, we have asked people with cancer to tell us what the major factors are that lead them to describe a day as good or bad. One of the most often mentioned factors that make a day bad is the presence of pain. The absence of pain is often given as a reason for labeling a day as good $(11,12)$.

The link between pain and the patient's cognitive, emotional, spiritual and social state is bidirectional - not only does the pain affect all aspects of the person, but all aspects of the person can contribute to the perception of pain. However, studies in this field tend to focus on one or a few of these domains but do not address them all at the same time. Some studies focus on physical/physiological contributors and treatments (13-16), while others focus on cognitive or psychological contributors and treatments (17-19). While these studies help us to understand the pain, unless we study all the important variables at the same time, we will not gain a broad view of their interaction with each other and will always be unable to understand fully the pain experience. We are not likely to achieve the best pain relief possible (that is, pain relief without toxicity) without addressing all the contributors to pain together (9). An exception to the usual focus on a narrow range of contributors to cancer pain and its treatment is the research program initiated by Betty Ferrell and her colleagues in 1989 (20-25). McMillan (26) has also addressed the relationship of different contributors to quality of life and cancer pain.

Let us now consider in greater detail the factors influencing the pain experience of the person with a life-threatening illness. We will not discuss the physical domain because its contribution to pain is undisputed. Although the ideas presented will apply to many life-threatening illnesses, because our experience is primarily with people who have cancer, we will focus on cancer pain. Many of these ideas have been discussed in Mount's chapter in Pat Wall's and Ron Melzack's Textbook of Pain (9). Where quotes from study participants are given, any information that could lead to identification of the participants has been changed to preserve their anonymity. In addition, interviews that were conducted in French have been translated into English. These quotes come from a qualitative study examining the contributors to the quality of life of palliative care patients with cancer carried out by the National Cancer Institute of Canada Sociobehavioural Cancer Research Network (12).

\section{PAIN AFFECTS ALL ASPECTS OF LIFE}

People in severe pain find that the pain becomes the focus of their life and robs them of the ability to enjoy life. The pain affects their cognitive status in that it is difficult to focus on anything else; their emotional status, in that they often become irritable if not clinically depressed; their physical status, such as mobility, ability to sleep and severity of other symptoms; their willingness to socialize, social status and dependency; and their existential and spiritual status, relationship to God, perception of meaning, and even whether they wish to go on living. Therefore, we recognize that if we are to measure the full impact of relief of severe pain, we must measure the effect on many aspects of life.

The following quote from a participant in our qualitative study (12) describes this overwhelming effect of pain and pain relief. We interviewed this woman in her home a few days after the unremitting pain she had experienced for almost two months was relieved by a change in analgesic medication. We asked her what was important to her quality of life.

I have been living with this cancer for five years now. And over time I've come to realize that quality of life is very influenced by pain. It depends on the amount of pain you have to endure.

I find that ideally, since there's no cure for this cancer, there's only one thing to aim for, to live fully. It depends on our attitude, the attitude of the patient concerning life, [and] everything is related to the pain. When you are free of pain, depending on the effort you put in, you can have a quality of life almost as good as, if not better than, some people who do not have this illness. So I think that the first responsibility of the doctors who work on your case, it must be to find a solution to control the pain... I lived through a very bad experience over the past two months. I had at least 7 weeks when I did not sleep more than 2 hours a night. In addition, I had lots of side effects, because they were increasing my painkillers. I got up to $60 \mathrm{mg}$ of the painkiller a day, so my stomach was really upside down, and in the end, I had nausea, and nausea and nausea, and now I see that it was caused by the painkiller...

I came to the point where I couldn't take it anymore. It affected my character. It affected my...my mental and psychological disposition. Nothing was worth the effort, and I was depressed, and... I have a very strong faith, and yet I even got to the point where I 
said: "My God, come and get me. It's not worth it. In any case there is really nothing more I can do to serve you..."

Then finally there was another doctor, my family doctor who took the situation in hand and who started me on a new painkiller. Then the first night I took it, already I slept four-and-a-half hours in a row. Then the second night I slept five, five-and-a half hours. Then for the last two nights I slept seven hours a night... But understand, I sleep, I sleep and I wake up rested, whereas before even the two short hours I slept before starting the new painkiller, ah... it was pain that woke me up. Is there anything more depressing than, than waking up in pain? Aaaaakkk! ... and when we speak of quality of life, I couldn't undertake anything. I couldn't undertake a bit of sewing, or go out, or do anything, because I knew I would be pain-free for not more than one-and-a-half to two hours. You get to the point where you live only to fight the damned pain.

In response to the research assistant's statement, "So I imagine you have rediscovered several aspects of your life that you had let go", the patient answered:

Absolutely. And I am re-awakening. I have the desire to do projects. Today is the birthday of my daughter, and I had her over for brunch!!! Today! Can you imagine that?

[Before] little by little I was going down, down, down...And I didn't realize it but the only goal I had was to see if I was capable of controlling the pain by playing with my dose of painkiller... it was my only preoccupation...

Now I have returned to what I was, I'd say to the quality of life I had nearly two years ago. I'm not naïve enough to believe that, you know... I am... it's not that my disease is getting better, it's that the pain is controlled. The pain is better controlled, and I'm thrilled because I have a quality of life. I'm not a vegetable. I accept that there's no cure for my cancer, so we do the best we can, and accept it... But oh, the first painkiller, it was beyond me, it was too much for me. Even the strongest dose no longer had an effect, and it gave me additional problems! It gave me dreadful nausea, and I vomited to the point where I didn't go out because it wasn't worth disturbing a friend, or whoever, to go out and then after 45 minutes all of a sudden say: "I feel dead, I feel dead, I have to go back home”. So I didn't go out anymore. Because of my stomach. I didn't digest that painkiller, so I didn't have any desire to eat. ... I really like good food, but I wasn't eating anymore...

Thirdly, a great pleasure in my life is my grandchildren who are three and one-and-a-half years old, but I couldn't take them on my knees; couldn't play on the ground with them;... I could no longer walk with them; I couldn't go to the park with them; I couldn't do any of it. You know, that was a great part of my reason for living. It was my grandchildren. This afternoon my grandson said: "Grandma! Grandma! You have no pain!!" No, grandma has no pain. "How come?" Even the little three year old noticed.

In addition, I really like music a lot, but you get no enjoyment in listening to music when you have pain. How do you think you can relax and listen to music when you can hardly move in bed without pain? And so it's come back, and I read. I read a lot, I'm a bookworm, but I wasn't able to read because... it's difficult to explain, to someone who hasn't lived through it, but pain like that, constantly, 24 hours a day for weeks, I wasn't even capable of concentrating...

She finished the interview by saying...

If you had a come a week ago when I was in pain, you would have seen a totally different person from what you see today.

\section{PSYCHOLOGICAL: FEARS AND ANXIETY}

Melzack (7) pointed out that past experience and cultural expectations influence the perception of pain. In our studies, even people who had not experienced cancer pain mentioned that the absence of pain contributed to them having a good day $(11,12)$. The expectation that cancer causes uncontrollable pain is so strong for many people that they consider each day without pain a blessing. This expectation is created not only by information from the media or stories they have heard, but often from personal experience with a family member or friend who had uncontrolled cancer pain. This is illustrated in the following quote from a man with lung cancer and brain metastases. His fear of pain is evident not only in the content of his speech, but also in the hesitation with which he discusses pain and his uncertain prognosis.

...they'll be doing the CAT scan on the 16th, so, as I say, I have to look at the brighter things. I've got a 50/50 chance. And then secondly, even if, ah, I draw the short straw, I ah, the place where, you know, it's in my brain so ah, your brain not having any nerves in it, I don't suffer any pain. I don't have any pain whatsoever...I know ah, of ah friends of mine who ah, have died of things like stomach cancer, and they had it terrible. I mean it's a terrible way to go. My friend used to just lay there screaming for medication, but his wife would go up and talk to them, and they said: "He's at the maximum dose. He can't have any more". I guess I have to consider myself fortunate that I don't have any pain...unless it spreads someplace else.

These fears increase anxiety, which can intensify the pain perceived (7). When one has a life-threatening illness there 
are also many causes of anxiety other than pain, or fear of it. For example, one of the main concerns of people with a lifethreatening illness is what will happen to their family, both during treatment and also when they die $(9,12)$. They may worry about a son or daughter (young or adult) who needs their help, or the patient may be the caretaker of an ill spouse or elderly parent. Concern for who will care for their loved ones when they are unable to do so creates much anxiety. Furthermore, simultaneous life crises are not infrequent, and contribute to their anxiety and potentially increase the pain.

Fear can also interfere with people's willingness to take pain medication and thus contribute to increased suffering. Many fear that they will become a 'drug addict' if they take morphine. Others may not know the word 'tolerance', but they believe that they need to save the strong pain medication for when the pain becomes unendurable, and that if they begin taking pain medication too early it will no longer be effective "when they really need it" (24).

\section{COGNITION}

Severe pain makes it difficult to focus on anything else. Biologically, we are programmed to pay attention to pain because in many situations this will ensure that we take the appropriate action to allow the necessary healing of the tissue damage signalled by the pain.

Melzack (7) gives powerful examples of how the contextual meaning of an injury greatly influences the associated perceived pain. For people with cancer, it is not only the intensity of the pain that affects quality of life, but the meaning of the pain as well $(9,25)$. The pain serves as a reminder of the cancer that might lead to death or further debilitation, or require further difficult treatments. Many pains experienced by people with cancer are interpreted by them or their family as a sign that anticancer treatment is not working and/or that the cancer is progressing. This is the case even when the pain may be due to the treatment itself or to an unrelated cause. The association of the pain with cancer, impending death and further debilitation can serve to increase anxiety and thereby increase the intensity of the pain, an example of the bidirectional effect that serves to augment the suffering caused by the pain. One man who was terminally ill said the following in response to the question "What contributes to your quality of life?".

\footnotetext{
Well, I suppose lack of pain would be one major item. Because if I don't have pain I can do things that I can't otherwise do. Not having the pain contributes to conversations with my wife, or with my relatives, or just with people in the hospital. I think it makes my life easier in that I'm not always concerned about why the pain is there. I know that there's cancer there, and if there is pain there your mind sort of works overtime and you start thinking about what the potential options are down the line. Of course it makes you start thinking about cancer and you know you are going to die. It affects you.
}

Interventions directed at changing cognitive patterns and a re-evaluation of the situation may help to reduce pain in these situations (17).

\section{SOCIAL}

When one is diagnosed with cancer, there are many social changes. There are changes in relationships $(9,12)$. Some good friends avoid the situation, leaving the person with cancer and their family feeling abandoned or ostracized (22). Sometimes acquaintances or newly made friends are much more supportive than anticipated; however, there is often a feeling of isolation, even in the midst of company, because others who have not had cancer cannot fully empathize with the experience. On the other hand, the strong support given to persons with cancer may make them feel more loved than before, allowing a focus on something positive rather than the pain (12). There are also changes in roles, which are difficult to adapt to $(9,12)$. The person with cancer must often leave the workforce, at least temporarily. Those who were volunteering may feel the loss of that role acutely. These were ways in which they contributed to society and can no longer do so. Furthermore, their role within the family changes because they are no longer able to carry out their usual tasks. These changes in the social domain may create emotional suffering that increases the pain. As described in the first quote above, the pain may serve to limit the person's social interactions, leading to withdrawal from an active social life. This in turn can result in the loss of potential sources of distraction from the pain, and enhance the isolation that may contribute to the pain. Interventions such as supportive group therapy have been shown to reduce cancer pain (27).

\section{SPIRITUAL AND EXISTENTIAL WELL-BEING}

To the extent that pain interferes with one's ability to participate actively in life, it can contribute to existential or spiritual suffering in that one can begin to question whether continued existence remains meaningful. The first quote above illustrates how the limitations caused by the pain led the woman to feel that life was no longer worth living because she could no longer serve God. People can also see pain as a punishment from God, leading them to question what they have done to warrant such suffering (25). In this sense pain can increase suffering in a way that is not simply physical.

Clinical experience suggests that cancer pain can be increased by spiritual or existential distress. The suffering experienced by those who feel that they have not accomplished anything worthwhile in life or have not been faithful to God may amplify the pain they experience. Fear of what happens after death may also contribute to pain in the present. Conversely, a return to a sense of inner peace, acceptance, meaning and connectedness may be associated with a lessening of pain (10). Appropriate clinical interventions (28) can help to reduce existential or spiritual distress, which may in turn alleviate pain or reduce the dose of analgesics required for pain control. 


\section{LOSS}

Most people who suffer from chronic pain experience losses in several aspects of their lives. Those who are dying of their cancer experience loss to an even greater extent; they face the permanent loss of everything that they know, and all of the future, with the exception of those who retain faith in an afterlife (9). Pain itself can be a cause of loss and a constant reminder of loss (23). Ongoing and anticipated losses affect all of the domains described above: cognitive, psychological, social, and spiritual and existential. While the losses cannot be prevented, clinical interventions in all of these domains can help the person facing death to cope with these losses. Failure to do so is likely to increase the cancer pain (29).

\section{CONCLUSIONS}

We need to explore the particular contributors to pain for a given individual and address them all to obtain optimal pain control with the least toxicity. Ron Melzack taught us that this is true for all types of pain. We have described some of the more common contributors to cancer pain. What is required for cancer pain research to proceed is a cancer pain classification system that takes into account not only the contribution of the tumour and anticancer treatment to the pain, but also the cognitive, psychological, social, spiritual and existential contributors to the pain itself or to the success or failure of treatments of all types. This type of classification system could be used in studies to test the effectiveness of all types of interventions (for example, cognitive, psychological, social, spiritual and others as well as pharmaceutical) and perhaps as a guide for choosing the most appropriate first line treatment (28). In a joint effort between the National Cancer Institute of Canada's Clinical Trials Group and its Sociobehavioural Cancer Research Network, with mentorship from Ron Melzack and international collaborators, we are beginning to develop such a cancer pain classification system.

\section{REFERENCES}

1. Melzack R, Ofiesh JG, Mount B. The Brompton mixture: Effects on pain in cancer patients. CMAJ 1976;115:125-9.

2. Cohen SR, Mount BM, Strobel MG, Bui F. The McGill Quality of Life Questionnaire: A measure of quality of life appropriate for people with advanced disease. A preliminary study of validity and acceptability. Palliat Med 1995;9:207-19.

3. Cohen SR, Mount BM, Tomas J, Mount L. Existential well-being is an important determinant of quality of life: evidence from the McGill Quality of Life Questionnaire. Cancer 1996;77:576-86.

4. Cohen SR, Hassan SA, Lapointe BM, Mount BM. HIV disease and AIDS: increasing importance of the existential domain in determining quality of life as T4 cell counts decrease. AIDS 1996;10:1421-7.

5. Cohen SR, Mount BM, Bruera E, Provost M, Rowe J, Tong K. Validity of the McGill Quality of Life Questionnaire in the palliative care setting. A multi-center Canadian study demonstrating the importance of the existential domain. Palliat Med 1997;11:3-20.
6. Melzack R, Wall PD. Pain mechanisms: A new theory. Science 1965;150:971-9.

7. Melzack R. The Puzzle of Pain. New York: Basic Books Inc, 1973.

8. Saunders D. The Management of Terminal Illness. London: London Hospital Medical Publication, 1967.

9. Mount BM. Psychological and social aspects of cancer pain. In: Wall PD, Melzack R, eds. Textbook of Pain. New York: Churchill Livingston, 1984;460-71.

10. Cohen SR, Mount BM. Quality of life in terminal illness: defining and measuring subjective well-being in the dying. J Palliat Care 1992;8:40-5.

11. Cohen SR, Mount BM. Living with cancer: 'Good days' and 'bad days'- what produces them? Can the McGill Quality of Life Questionnaire distinguish between them? Cancer 2000;89:1854-65.

12. Cohen SR, Bunston T, Leis AM, et al. Domains relevant to the quality of life of palliative care patients with cancer. Canadian Palliative Care Conference, Saskatoon, September 29-30, 1999. (Abst)

13. Elliot KJ, Portenoy RK. Cancer pain: pathophysiology and syndromes. In: Yaksh TL, Lynch C, Zapol WM, eds. Anesthesia: Biologic Foundations. Philadelphia, Lippincott-Raven Publishers, 1997.

14. Ripamonti C, Zecca E, Bruera E. An update on the clinical use of methadone for cancer pain. Pain 1997;70:109-15.

15. Mercadante S. Problems of long-term spinal opioid treatment in advanced cancer patients. Pain 1999;79:1-13.

16. Nelson KA, Glare PA, Walsh D, Groh ES. A prospective, withinpatient, crossover study of continuous intravenous and subcutaneous morphine for chronic cancer pain. J Pain Symptom Manage 1997; 13:262-7.

17. Trijsburg RW, van knippenbberg FCE, Rijpma SE. Effects of psychological treatment on cancer patients: A critical review. Psychosom Med 1992;54;489-517.

18. Elliot BA, Elliot TE, Murray DM, Braun BL, Johnson KM. Patients and family members: The role of knowledge and attitudes in cancer pain. J Pain Symptom Manage 1996;12:209-20.

19. Strang P. Emotional and social aspects of cancer pain. Acta Oncol 1992;31:323-6.

20. Ferrell BA, Wisdom C, Wenzl C. Quality of life as an outcome variable in the management of cancer pain. Cancer 1989;63:2321-7.

21. Padilla G, Ferrell BR, Grant M, Rhiner M. Defining the content domain of quality of life for cancer patients with pain. Cancer Nurs 1990;13:108-15.

22. Ferrell BR, Johnston Taylor E, Grant M, Fowler M, Corbisiero RM. Pain management at home. Struggle, comfort, and mission. Cancer Nurs 1993;16:169-78.

23. Rhiner M, Ferrell BR, Ferrell B, Grant MM. A structured nondrug intervention program for cancer pain. Cancer Pract 1993;1:137-43.

24. Ferrell BR, Ferrell BA, Ahn C, Tran K. Pain management for elderly patients with cancer at home. Cancer 1994;74(7 Suppl):2139-46.

25. Ferrell BR, Dean G. The meaning of cancer pain. Semin Oncol Nurs 1995;11:17-22.

26. McMillan SC. Pain and pain relief experienced by hospice patients with cancer. Cancer Nurs 1996;19:298-307.

27. Spiegel D, Bloom JR, Yalom I. Group support for patients with metastatic cancer. Arch Gen Psychiatry 1981;38:527-33.

28. Mount BM, Kearney M. Existential and spiritual suffering in the management of advanced cancer. In: Cherny N, Catane R, Gelmon K, Glatstein E, Markman M, Richards M. The Management of Advanced Cancer. Oxford: Oxford University Press. (In press)

29. Boisvert M, Cohen SR. Opioid use in advanced malignant disease: why do different centers use vastly different doses? A plea for standardized reporting. J Pain Symptom Manage 1995;10:632-8. 


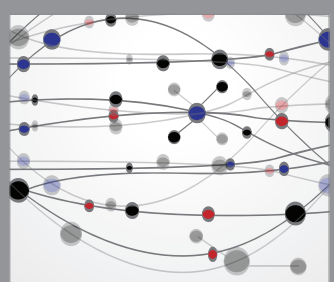

The Scientific World Journal
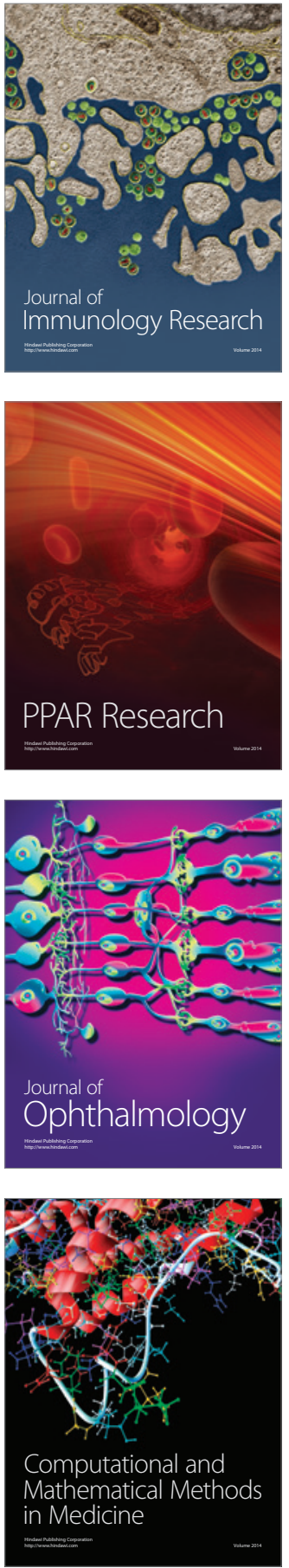

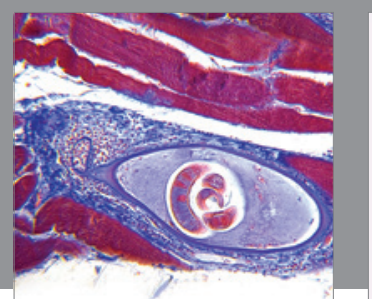

Gastroenterology Research and Practice

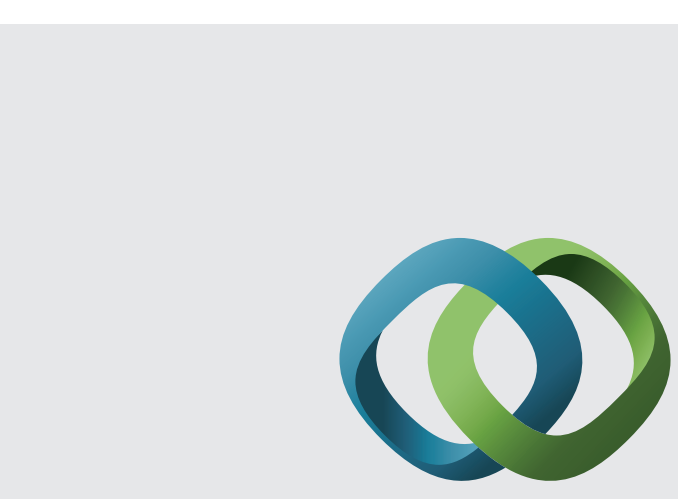

\section{Hindawi}

Submit your manuscripts at

http://www.hindawi.com
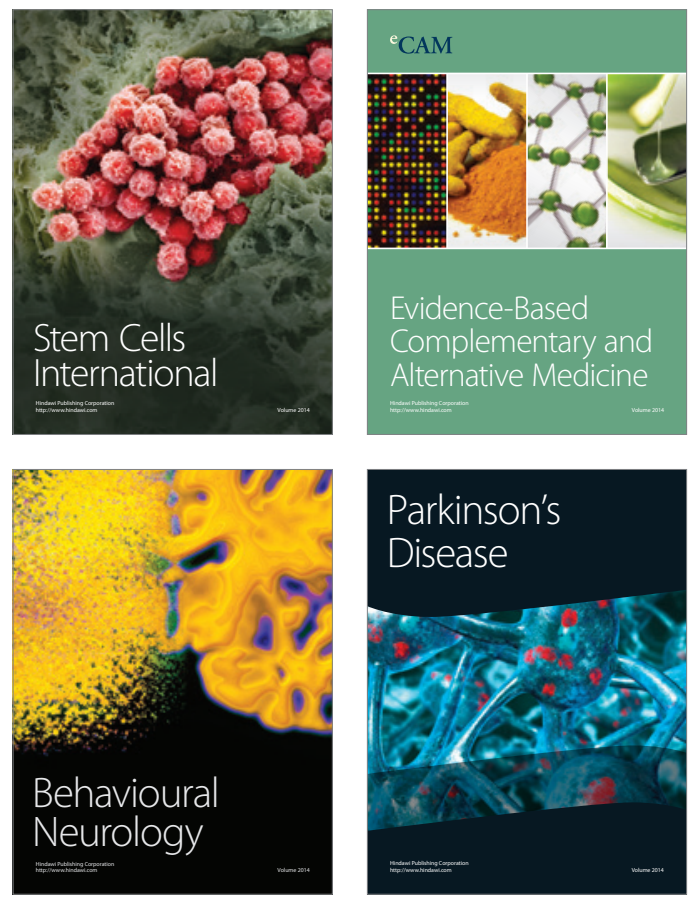
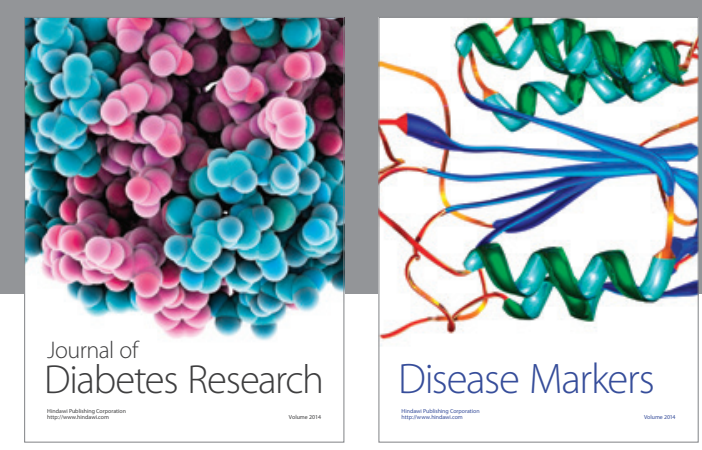

Disease Markers
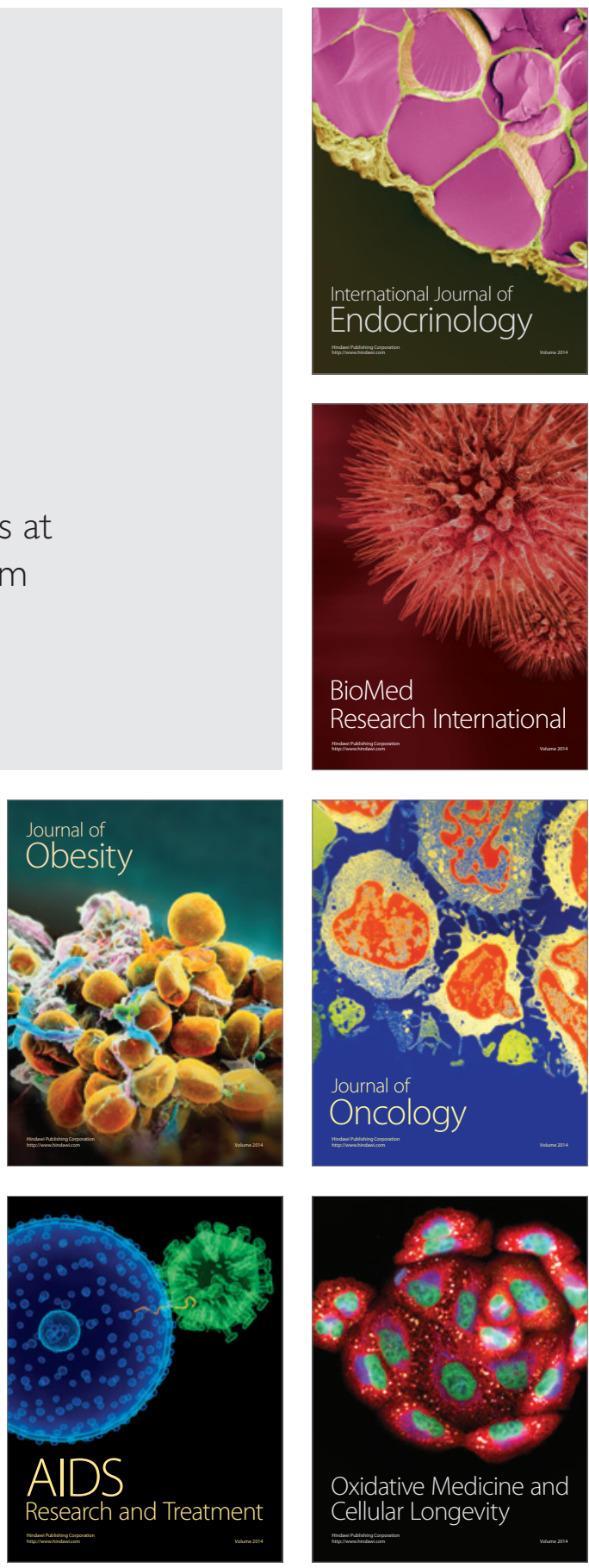